05

\title{
Магнитные свойства прессованных нанопорошков гексаферрита бария
}

\author{
(C) А.В. Тимофреев, В.Г. Костишин, Д.Б. Макеев, Д.Н. Читанов \\ Национальный исследовательский технологический университет „МИСиС“, \\ 119049 Москва, Россия \\ e-mail: andtim2011@gmail.com
}

Поступило в Редакцию 28 декабря 2018 г.

В окончательной редакции 28 декабря 2018 г.

Принято к публикации 29 апреля 2019 г.

Методами магнитно-силовой микроскопии и магнитометрии исследованы магнитные характеристики прессованных наноразмерных порошков $\mathrm{BaFe}_{12} \mathrm{O}_{19}$. Порошки были получены методом химического соосаждения. Обнаружена магнитная анизотропия типа „легкая плоскость“, образованная после операции прессования. Обсуждена природа появления анизотропии.

Ключевые слова: гексаферрит бария, нанопорошки, прессование, химическое соосаждение.

DOI: 10.21883/JTF.2019.10.48173.450-18

\section{Введение}

Феррит бария с гексагональной молекулярной структурой типа $\mathrm{M} \mathrm{BaFe}_{12} \mathrm{O}_{19}$ - широко известный на сегодняшний день высокопроизводительный постоянный магнитный материал, занимающий большую долю на рынке твердых магнитных материалов. Его главными характерными особенностями являются: довольно большая магнитокристаллическая анизотропия, высокая температура Кюри, относительно большая намагниченность, а также превосходная химическая и антикоррозионная стойкость $[1,2]$.

Чтобы в полной мере проявлять свои исключительные свойства, частицы феррита бария должны быть монодоменными с хорошей химической однородностью и с небольшим разбросом по размерам. Особенный интерес к этим наноразмерным частицам заключается в возможности влиять на их физические свойства путем манипулирования размером, составом, расстоянием между частицами. Недавние исследования показали, что технологии обработки существенно влияют на физические свойства наночастиц [3]. Поскольку размер кристаллитов, размер частиц и межчастичное расстояние оказывают наибольшее влияние на магнитные свойства, идеальный метод синтеза должен обеспечивать контролируемость этих параметров [4-7]. Известно множество способов получения как порошков гексаферритов, так и готовых изделий в виде брикетов различных форм.

Цель настоящей работы - оценить влияние прессования наноразмерных порошков гексаферрита бария типа М, имеющих анизотропную форму, на свойства прессовок.

\section{1. Экспериментальная часть}

\section{1. Подготовка образцов}

Синтез порошка гексаферрита бария типа М проводили методом химического соосаждения. Использованная технология синтеза детально описана в работе [8]. Наночастицы имели характерную анизотропную форму с диапазоном размеров от 70 до $240 \mathrm{~nm}$. Далее навески порошка весом $0.2 \mathrm{~g}$ были помещены в пресс-форму. Затем с помощью гидравлического пресса были сформированы таблетки диаметром $7 \mathrm{~mm}$ и толщиной $2 \mathrm{~mm}$. Усилие сжатия составляло $300 \mathrm{kgf} / \mathrm{cm}^{2}$. Целостность образцов нарушена не была.

После прессования образцы были уложены в специальные керамические кюветы. Кюветы, в свою очередь, были помещены в высокотемпературную муфельную печь для последующего спекания в течение $2 \mathrm{~h}$ при $1100^{\circ} \mathrm{C}$. После спекания половину образцов вынимали из рабочей зоны (закаленные образцы), а оставшиеся образцы остывали в камере печи вместе с печкой в течение $6 \mathrm{~h}$ (выдержанные образцы). Сделано это было для того, чтобы выяснить, как именно резкое охлаждение (закалка) повлияет на физические и магнитные характеристики образцов.

\section{2. Методика экспериментальных исследований}

Спрессованные образцы были исследованы при помощи сканирующего зондового микроскопа (С3М) NT-MDT ИНТЕГРА Прима с целью выявления топографических особенностей поверхности и дальнодействующих приповерхностных магнитных сил. Данный СЗМ позволяет проводить исследования как в воздушной среде, так и в вакууме. Измерения проводятся при помощи специального кантилевера MFM01 с резонансной частотой $53 \mathrm{kHz}$, покрытого тонкой магнитной пленкой $\mathrm{CoCr}$. Зонд перемещался вдоль исследуемой поверхности в бесконтактном или полуконтактном режиме. На кантилевер падает лазерный луч, который, отражаясь от него, попадает на фотодетектор. Магнитный кантилевер, взаимодействуя с поверхностью, меняет свое положение 

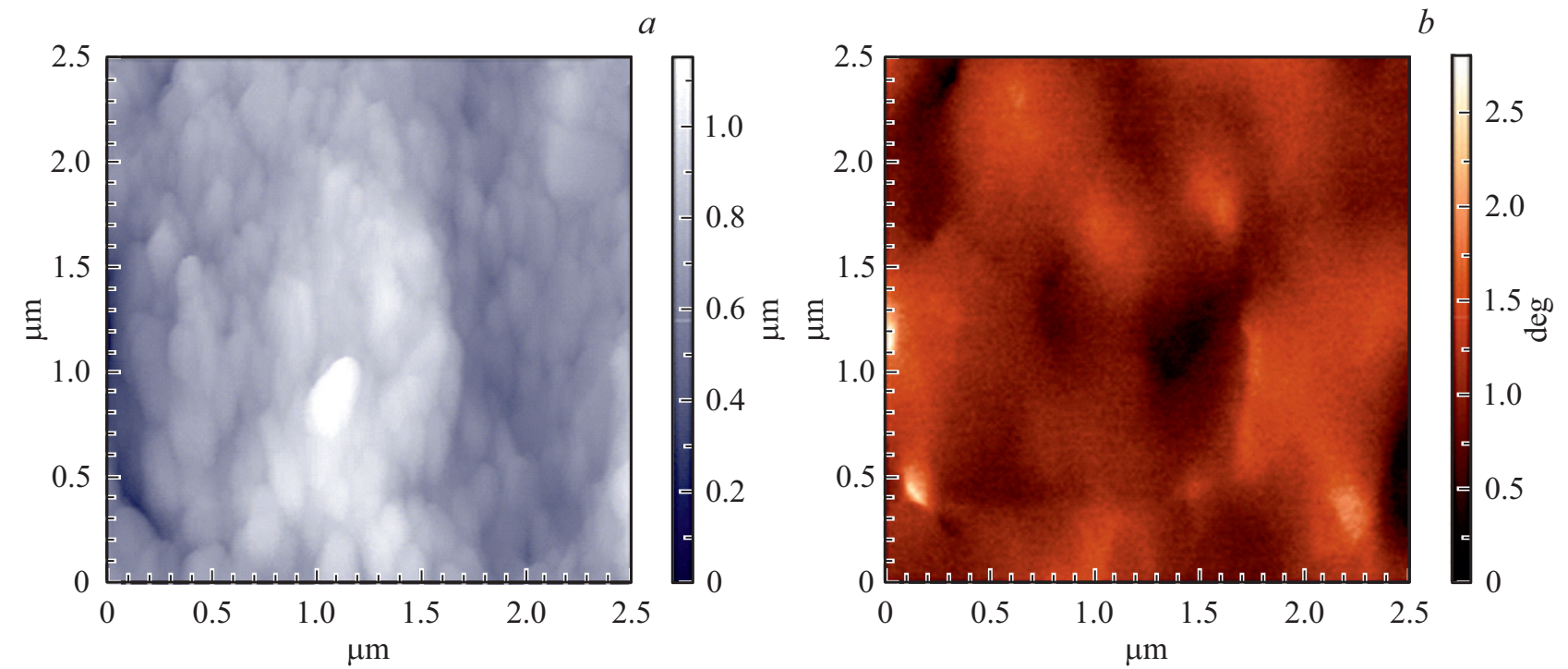

Рис. 1. Характерная топография поверхности спрессованного образца (с температурной выдержкой $)$ размерами $2.5 \times 2.5 \mu \mathrm{m}(a)$ и распределение градиента поверхностных магнитных сил при $D_{z}=750 \mathrm{~nm}(b)$.
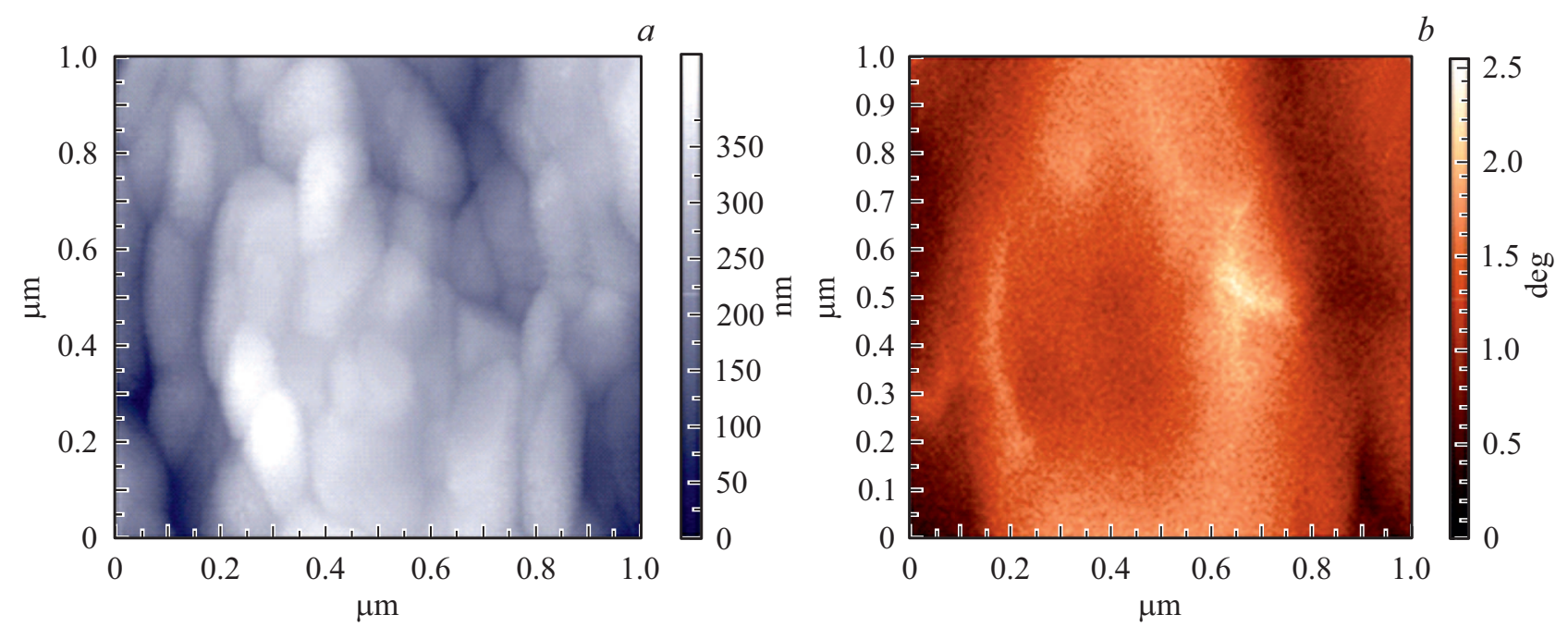

Рис. 2. Характерная топография поверхности спрессованного образца (закаленного) размерами $1 \times 1 \mu \mathrm{m}(a)$ и распределение градиента поверхностных магнитных сил при $D_{z}=500 \mathrm{~nm}(b)$.

Основные магнитные характеристики полученных гексагональных ферритовых образцов $\mathrm{BaFe}_{12} \mathrm{O}_{19}$

\begin{tabular}{|c|c|c|c|}
\hline $\begin{array}{c}\text { Полученные } \\
\text { образцы } \mathrm{BaFe}_{12} \mathrm{O}_{19}\end{array}$ & $\begin{array}{c}\text { Намагниченность } \\
\text { насыщения } \\
M_{s}, \mathrm{emu} / \mathrm{g}\end{array}$ & $\begin{array}{c}\text { Остаточная } \\
\text { намагниченность } \\
M_{r}, \text { emu/g }\end{array}$ & $\begin{array}{c}\text { Коэрцитивная сила } \\
\text { по намагниченности } \\
H_{c}, \text { Oе }\end{array}$ \\
\hline Нанопорошок & 29.23 & 18.1 & 3490 \\
\hline $\begin{array}{c}\text { Спрессованный, } \\
\text { без температурной } \\
\text { выдержки } \\
\text { (закаленный) }\end{array}$ & 37.46 & 24.12 & 3838 \\
\hline $\begin{array}{c}\text { Спрессованный, } \\
\text { выдержанный } \\
\text { в печке }\end{array}$ & 60.71 & 39.2 & 3885 \\
\hline
\end{tabular}


и отклоняет луч. Программное обеспечение Nova Px, обрабатывая получаемый фотодетектором сигнал, преобразует его в изображение. В двухпроходной методике зонд сначала регистрирует сигнал поверхности образца, а затем поднимается на некоторое расстояние $D_{z}$ над поверхностью, выдерживая его в постоянном режиме, и реагирует только на магнитные силы.

Магнитные параметры объектов исследования изучались на модернизированном вибрационном магнитометpe ВM-07 при комнатной температуре и нормальном атмосферном давлении. Принцип работы устройства базируется на измерении магнитного момента образца, который колеблется в однородном магнитном поле. Модернизация вибромагнитометра заключалась в том, что двухкоординатный самописец был заменен на электронный регистратор сигналов и селективный усилитель, соединенные с персональным компьютером для автоматизации процесса измерения.

\section{2. Результаты и обсуждение}

Результаты исследования методом атомно-силовой микроскопии поверхностей спрессованных нанопорошков представлены на рис. $1, a, 2, a$. Видно, что зерна на поверхностях обоих образцов вытянуты вдоль плоскости таблетки и имеют характерную ориентацию, перпендикулярную оси прессования. Таким образом, достигается равновесное положение. Размеры микрочастиц и морфология обусловлены разными способами охлаждения после спекания. Так, бо́льшими геометрическими размерами обладают зерна образцов, которые остывали вместе с печью: по длине $135-340 \mathrm{~nm}$ против $110-290 \mathrm{~nm}$ и по ширине $65-190 \mathrm{~nm}$ против $60-130 \mathrm{~nm}$ соответственно. Также им присуща более сильная анизотропия кристаллитов.

На рис. $1, b-2, b$ представлены изображения, полученные методом магнитно-силовой микроскопии. Хоть регистрация сигнала воздействия приповерхностных магнитных сил на намагниченный кантилевер проводилась при разных расстояниях $D_{z}$ и при разных масштабах, более сильные отклонения зонда, учитывая опять же расстояние $D_{z}$, наблюдаются для спрессованных образцов с температурной выдержкой. Усиление взаимодействия кантилевера с комплексом поверхностных магнитных сил происходит, когда кантилевер сканирует низменности между микрочастицами - такие области на снимках являются светлыми. Когда кантилевер находится только над зерном в топографической высоте, отсутствует вклад межзеренных магнитных взаимодействий - такие области показаны темным. Исходя из вышесказанного, можно предположить, что вектора намагниченности лежат в плоскости спеченных таблеток.

Для подтверждения этого заключения петли магнитного гистерезиса образцов регистрировались в двух геометриях: в магнитном поле, перпендикулярном $(\perp)$ и параллельном $(\|)$ плоскости таблетки.

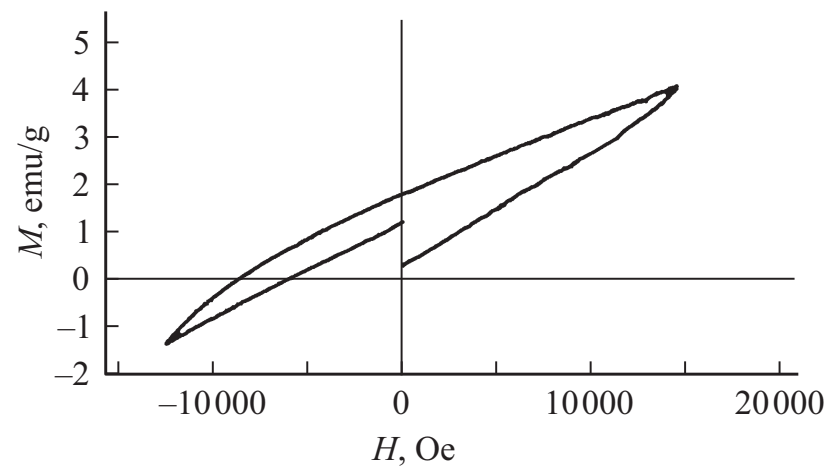

Рис. 3. Петля гистерезиса образца в поперечном магнитном поле $(\mathbf{H} \perp$ плоскости таблетки).

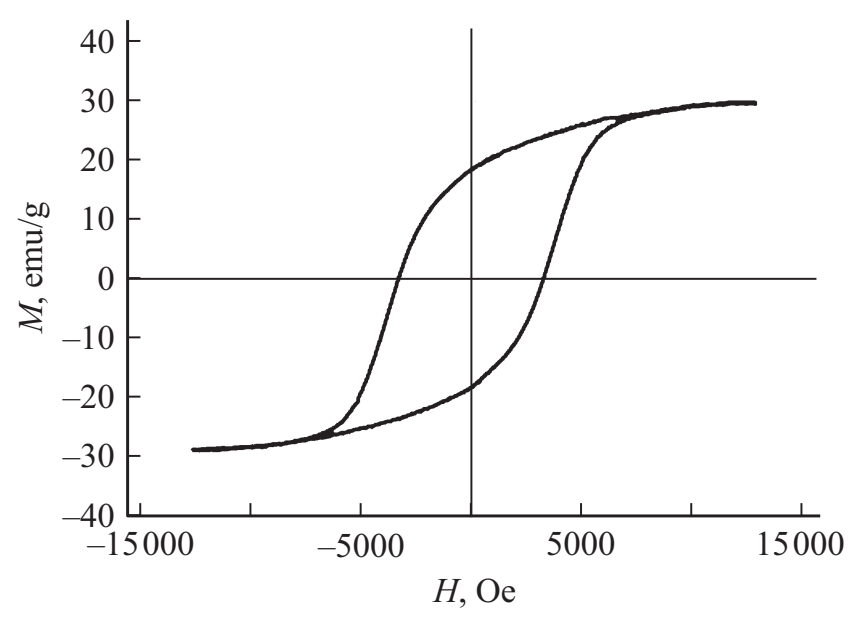

Рис. 4. Петля гистерезиса наноразмерного порошка, спеченного при $1000^{\circ} \mathrm{C}$.

Результаты этого исследования представлены на рис. 3. На нем видно, что прикладываемого поля $15 \mathrm{kOe}$ не хватает для намагничивания образца до насыщения в геометрии $\mathbf{H} \perp$ плоскости образца, следовательно, ось легкого намагничивания в данном направлении отсутствует.

Характерные петли магнитного гистерезиса и основные магнитные характеристики исследованных образцов представлены в таблице и на рис. 4,5.

Все изготовленные материалы достигают насыщения примерно при 10000 Ое. Выдержанный в печи образец и закаленный показывают значительно лучшие характеристики в сравнении с нанопорошком. Так, у обоих образцов значительно выросла коэрцитивная сила $H_{c}$ : на 645 и на 598 Ое для выдержанного и закаленного образцов соответственно. Для образца с выдержкой произошло более чем двукратное увеличение магнитного момента в насыщенном состоянии $M_{s}$ и значения остаточной намагниченности $M_{r}$, а именно в 2.08 раз и в 2.17 раз соответственно. Для образца без выдержки рост был менее значительным: в 1.28 раз в намагниченном состоянии и в 1.33 раз для остаточной намагниченности. 

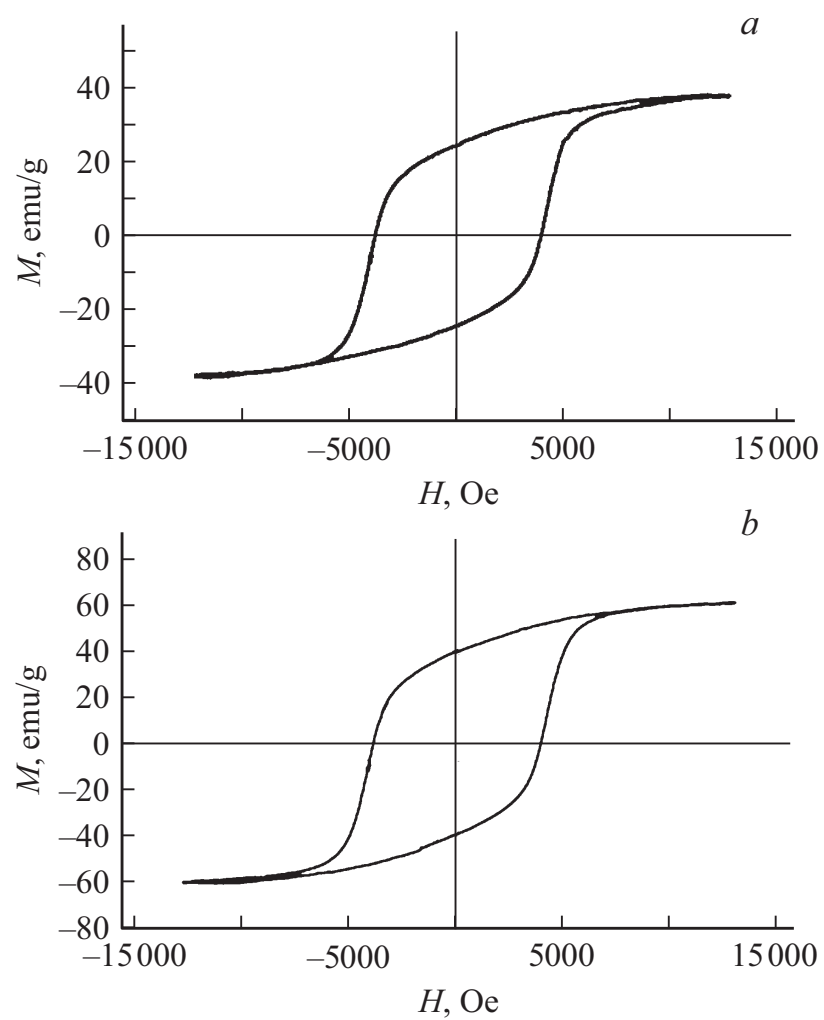

Pис. 5. Петли гистерезиса: $a$ - выдержанного образца и $b-$ образца без выдержки (Н $\|$ плоскости пленки).

Таким образом, спрессованный порошок, состоящий из наночастиц гексаферрита бария $\mathrm{BaFe}_{12} \mathrm{O}_{19}$ и не испытывающий жестких перепадов температур сразу после спекания (закаливания), обладает наилучшими магнитными свойствами.

\section{Заключение}

Магнитная анизотропия объектов исследования возникла вследствие прессования наноразмерного порошка гексагонального феррита бария типа М. Данные СЗМ показали, что вытянутые частицы гексаферрита характерно ориентированы в плоскости спрессованной таблетки, и магнитные всплески наблюдаются в низовых областях поверхности между зернами. Показано проявление анизотропии при разных направлениях намагничивания относительно плоскости образца. Установлено, что ось легкого намагничивания располагается вдоль плоскости прессования. Показано, что после прессования и спекания первичный нанопорошок $\mathrm{BaFe}_{12} \mathrm{O}_{19}$ демонстрирует значительный рост своих характеристик, а плавное охлаждение образцов в печи обеспечивает высокое качество готового продукта.

\section{Благодарности}

Авторы благодарны профессору Шипко М.Н. за обсуждение результатов работы.

\section{Финансирование работы}

Работа выполнена в рамках гранта президента № МК-1041.2017.8.

\section{Конфликт интересов}

Авторы заявляют, что у них нет конфликта интересов.

\section{Список литературы}

[1] Куничев А.В., Подольский А.В., Сидоров И.Н. Ферриты. Магниты и магнитные системы. М.: ЛИК, 2004. 358 с.

[2] Летюк Л.М., Костишин В.Г., Гончар А.В. Технология ферритовых материалов магнитоэлектроники. М.: МИСиС, 2005. $352 \mathrm{c}$.

[3] Pullar R.C. // Prog. Mater. Sci. 2012. Vol. 57. N 7. P. 1191-1334. DOI: 10.1016/j.pmatsci.2012.04.001

[4] Makovec D., Primc D., Sturm S., Korde A., Hanzel D., Drofenik M. // J. Solid State Chem. 2012. Vol. 196. P. 63-71. DOI: $10.1016 /$ j.jssc.2012.07.043

[5] El Shater R.E., El-Ghazzawy E.H., El-Nimr M.K. // J. Alloys Compd. 2018. Vol. 739. P. 327-334. DOI: $10.1016 /$ j.jallcom.2017.12.228

[6] Liu C., Liu X., Feng S., Rehman K.M.U., Li M., Zhang C., Li H., Meng X. // J. Supercond. Nov. Magn. 2018. Vol. 31. P. 933-937. DOI: 10.1007/s10948-017-4283-2

[7] Li Y., Xia A., Jin C. // J. Mater. Sci.: Mater. Electron. 2016. Vol. 27. N 10. P. 10864-10868. DOI: $10.1007 / \mathrm{s} 10854-016-5195-9$

[8] Костишин В.Г., Тимофеев А.В., Читанов Д.Н. // Хим. техн. 2018. № 1. C. $11-15$. 